\title{
Quality of Life of Patients Undergoing Maintenance Hemodialysis in Erbil City
}

\author{
Haval Mohammed Qader; Department of Nursing, College of Nursing, Hawler Medical University, Erbil, Iraq. \\ Vian Afan Naqshbandi; Department of Nursing, College of Nursing, Hawler Medical University, Erbil, Iraq.

\begin{abstract}
Background and objectives: Chronic renal disease is one of the developing issues everywhere throughout the world. Health related quality of life is a critical, yet is disregarded part of chronic kidney disease care. Alongside survival and different kinds of clinical results, patient quality of life is an important marker of the effectiveness of the medical care they get. The study aimed to evaluate the quality of life of patients undergoing maintenance hemodialysis in Erbil city.

Methods: A descriptive study design conducted in the Erbil Dialysis Centre and Dialysis unit at Erbil Teaching Hospital. The sample include 262 end stage renal failure patients undergoing hemodialysis for at least 2 months, the Kidney Diseases Quality of Life short form questionnaire were used to obtain the information through structured interview. The study lasted from 24 March to 30 May 2018. The data were analyzed through descriptive statistical approach, chi-square test and person correlation analysis.

Results: Participants were 262 patients with mean age of $55.55 \pm 13.831$ years, $52.3 \%$ were female, $92 \%$ were married, $46.2 \%$ were illiterate and $66.4 \%$ were from rural area. The overall Quality of Life score was higher in male patients than female. About $61 \%$ of patients had below average Quality of Life. Regarding the Quality of Life domains, out of seven domains only two of them (symptoms/ problems and quality of social interaction domains) were at average level of quality of life, the rest domains were below average level. The results of the study revealed that there is significant relationship between Quality of Life score and level of education.

Conclusion: According to the finding of the study, the patients with end stage renal failure undergoing hemodialysis had poor Quality of Life in most domains and the study found that there were a significant relationship between patients education and there quality of life.
\end{abstract}

Keywords: End Stage Renal Failure, Hemodialysis, Quality Of Life, Kidney Diseases Quality of Life short form .

Received: $25 / 7 / 2018$

Accepted: $17 / 12 / 2018$

Published: 30/5/2019

\section{INTRODUCTION}

Chronic Kidney Disease (CKD) is an increasing worldwide public health concern. It is distinguished by an irreversible deterioration of renal function that can lead to EndStage Renal Disease (ESRD), which necessitates therapy with Renal Replacement
Therapy (RRT) such as renal transplant or Hemodialysis (HD). HD is one of the most effective therapeutic techniques for patients with ESRD second to renal transplantation but is costly and tiresome therapy for patients with ESRD[1] Current statistics indicate an increase in patient's life time 
due to haemodialysis. Dialysis like other treatment types can result in improvement and remission of patients. However, the side effects of dialysis may reduce the Quality Of Life (QOL) of patients and lead to faintness and inability in various aspects of life[2].

World Health Organization's (WHO) defined QOL as "individuals' perception of their position in life in the context of the culture and value systems in which they live and in relation to their goals, expectations, standards and concerns". It is a broad ranging concept affected by the person's complex physical health, psychological state, level of independence, social relationships, personal beliefs and their relationship to salient features of their environment[3].

Quality of Life measures are subjective or objective, functional or satisfaction-based, and generic or disease-specific. Recent studies showed an association between assessment of QOL and morbidity and mortality in end-stage renal disease patients. [4].

According to Sapkota and his colleagues has been estimated that over 1.1 million people are currently on Maintenance Hemodialysis (MHD) globally and this figure is increasing by $7 \%$ every year[5].

The End-Stage Renal Disease (ESRD) patients initiating Renal Replacement Therapy (RRT) experience significant morbidity and limitations in quality of life[6,7].

substantial reductions in patients' involvement in social and recreational activities, freedom, and abilities to work and travel, which have been associated with poorer overall health status and survival[6,8].

Health-Related Quality Of Life (HRQOL) has become increasingly important as an outcome measure of Renal Replacement Therapy (RRT). The traditional focus on the improvement of survival has recently shifted to include a much stronger emphasis on quality of life[11]. Health-Related Quality Of Life (HRQOL) represents the impact of the disease or its treatment on the subjective feelings of patients about their physical, mental, spiritual, emotional, social and functional wellbeing. (HRQOL) deteriorates as kidney function worsens and is an independent risk factor for mortality in dialysis patients[12]. This study aimed to assess the quality of life of patients with End Stage Renal Failure undergoing maintenance hemodialysis in Erbil city and to find out the association between quality of life and sociodemographic characteristics (age, gender, marital status and educational level).

\section{METHODS}

A descriptive study was conducted with patients with end stage renal failure undergoing hemodialysis treatment in Erbil city. The study conducted at Erbil Dialysis Center and Dialysis Unit at Erbil Teaching Hospital during March 24 to May 30, 2018. The sample of the study included all adult patients with end stage renal failure who had maintenance hemodialysis were attending to Erbil Dialysis Center and dialysis unit at Erbil Teaching Hospital; three session per week which include 125 males and 137 females, the patient with psychological disorder, very tired patients and new cases were excluded.

The researcher obtained official acceptance letter for conducting this study; oral informed consent obtained from participant in the study. A questionnaire prepared by the researcher to obtain data for this study and the Kidney Diseases Quality of Life Short Form KDQOL SF questionnaire were used. The questionnaire is reliable and recommended by the National Kidney Foundation. The pilot study was carried out in February 2018, the results of two checking (test and re-test) were analysed to find out the reliability by calculating 
Cronbach's Coefficient Correlation it was 0.82 .

Structured interview utilized to obtained patients responds about the questionnaire. The data collected within the first 2 hours after the initiation of hemodialysis in order to ensure that patients were not suffering from any dialysis-related discomfort. Each interview spent approximately $20-25$ minutes. Each item (question) is put on a 0 to 100 range so that the lowest and highest possible score were set at 0 and 100, respectively. Scores represented the percentage of total possible score achieved. The scores for each domain were classified in categories of below average $\geq 33$, average 34-67, and above average 68-100 according to the KDQOL of Medical Education Institute [13]. Data were organized and coded into the computer files; Statistical Package for Social Science (SPSS) version 23 omit was used. Descriptive statistical analysis (Frequency, Percentage, Mean and Standard deviation) and Chi-Square test or Fisher's Exact Test for categorical variables was used. The correlation between domains performed using person correlation coefficient.

\section{RESULTS}

A total of 262 End Stage Renal Failure (ESRD) patients with a mean age of 55.55 \pm 13.83 years on HD were included, and the highest percentage of the patients $39.3 \%$ were within the age groups 48-62 years and there were more females than males $52.3 \%$ vs $47.7 \%$. Most of them were married $92 \%$. Near of half of the sample was illiterate $46.2 \%$. About $66.4 \%$ of the study population were living in rural areas. The baseline demographic characteristics are shown in Table 1.

Table 2 shows the distribution of scores for the seven domains of KDQOL SF. Most of the domains scores ranked below average level in the all domains except symptoms/ problems and quality of social interaction domains which ranked average level.

Table 1: Sociodemographic characteristics of study samples

\begin{tabular}{|c|c|c|c|}
\hline Variables & & $\begin{array}{c}F \\
(n=262)\end{array}$ & $\%$ \\
\hline \multicolumn{2}{|c|}{$\begin{array}{l}\text { Mean age } \pm \text { Standard } \\
\text { deviation }\end{array}$} & \multicolumn{2}{|c|}{$55.55 \pm 13.831$} \\
\hline \multirow{5}{*}{$\begin{array}{l}\text { Age } \\
\text { groups }\end{array}$} & $18-32$ & 20 & $7.63 \%$ \\
\hline & $33-47$ & 47 & $17.93 \%$ \\
\hline & $48-62$ & 103 & $39.31 \%$ \\
\hline & $63-77$ & 83 & $31.7 \%$ \\
\hline & $78-92$ & 9 & $3.43 \%$ \\
\hline \multirow[t]{2}{*}{ Gender } & Male & 125 & $47.7 \%$ \\
\hline & Female & 137 & $52.3 \%$ \\
\hline \multirow{5}{*}{$\begin{array}{l}\text { Marital } \\
\text { status }\end{array}$} & Single & 16 & $6.1 \%$ \\
\hline & Married & 241 & $92.0 \%$ \\
\hline & Widow/ & & \\
\hline & Widowed & 4 & $1.5 \%$ \\
\hline & Separated & 1 & $0.4 \%$ \\
\hline \multirow{6}{*}{$\begin{array}{l}\text { Educa- } \\
\text { tional } \\
\text { level }\end{array}$} & Illiterate & 121 & $46.2 \%$ \\
\hline & $\begin{array}{l}\text { Primary } \\
\text { school }\end{array}$ & 74 & $28.24 \%$ \\
\hline & $\begin{array}{l}\text { Intermedi- } \\
\text { ate school }\end{array}$ & 47 & $17.93 \%$ \\
\hline & $\begin{array}{l}\text { High } \\
\text { school or } \\
\text { vocational }\end{array}$ & 11 & $4.2 \%$ \\
\hline & Institute & & \\
\hline & and above & 9 & $3.43 \%$ \\
\hline \multirow{2}{*}{$\begin{array}{l}\text { Residen- } \\
\text { tial area }\end{array}$} & Rural & 174 & $66.4 \%$ \\
\hline & Urban & 88 & $33.6 \%$ \\
\hline
\end{tabular}


Table 2: Sociodemographic characteristics of study samples

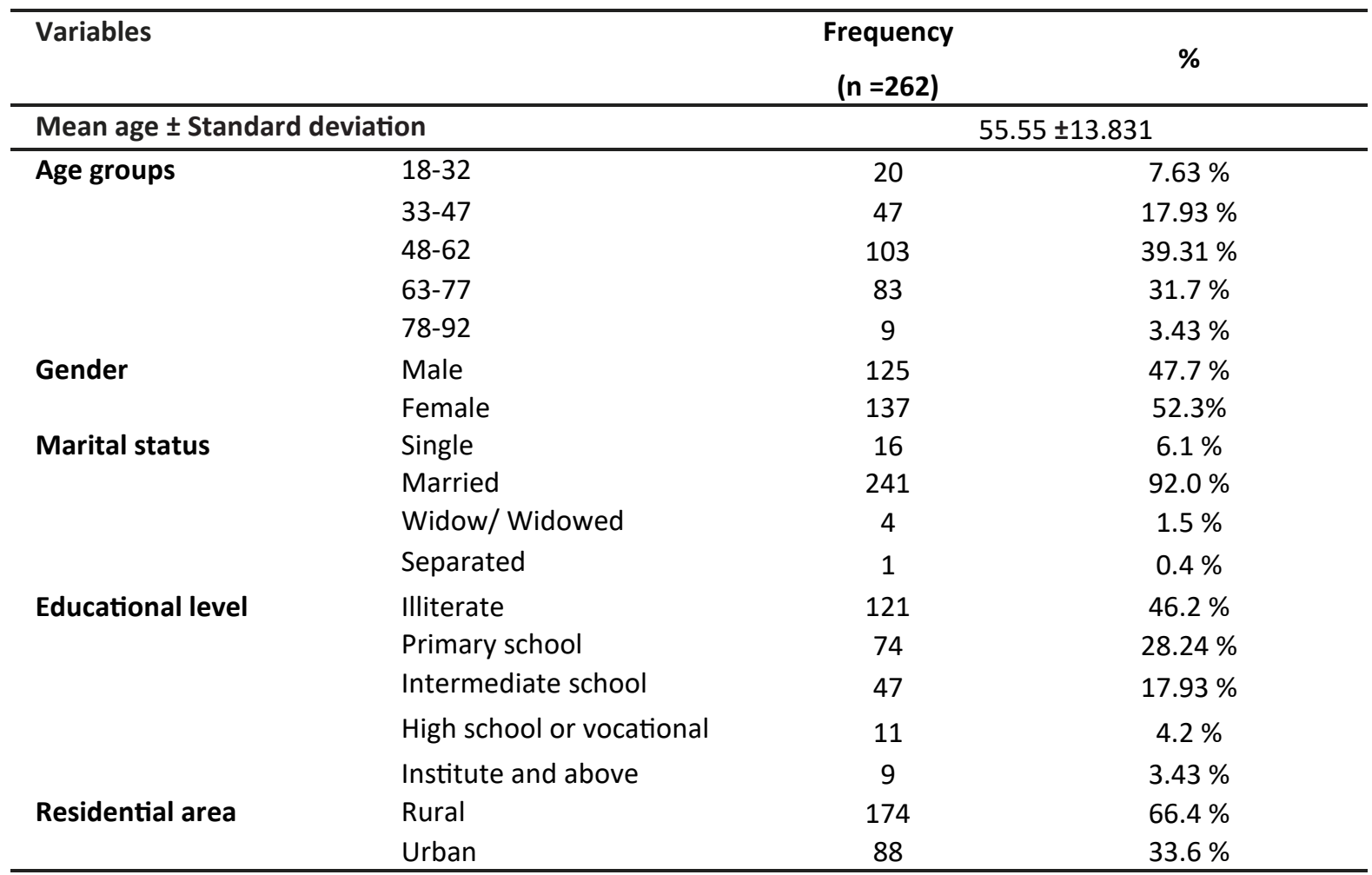

Table 3: Association of quality of life levels of patients with their sociodemographic characteristics.

\begin{tabular}{|c|c|c|c|c|}
\hline \multirow{3}{*}{$\begin{array}{l}\text { Sociodemographic charac- } \\
\text { teristics }\end{array}$} & \multicolumn{4}{|c|}{ Overall QOL score } \\
\hline & Above average & Average & Below average & P-Value \\
\hline & Frequency (\%) & Frequency (\%) & Frequency (\%) & \\
\hline \multicolumn{5}{|l|}{ Gender } \\
\hline Male & $0(0)$ & $53(42.4)$ & $72(57.6)$ & \multirow{2}{*}{0.271} \\
\hline Female & $0(0)$ & $49(35.8)$ & $88(64.2)$ & \\
\hline \multicolumn{4}{|l|}{ Age groups (years) } & \multirow[t]{6}{*}{0.491} \\
\hline $18-32$ & $0(0)$ & $8(40)$ & $12(60)$ & \\
\hline $33-47$ & $0(0)$ & $19(40.4)$ & $28(59.6)$ & \\
\hline $48-62$ & $0(0)$ & $43(41.7)$ & $60(58.3)$ & \\
\hline $63-77$ & $0(0)$ & $31(37.3)$ & $52(62.7)$ & \\
\hline 78-92 & $0(0)$ & $1(11.1)$ & $8(88.9)$ & \\
\hline \multirow{2}{*}{$\begin{array}{l}\text { Educational level } \\
\text { Illiterate }\end{array}$} & & & & \multirow[t]{6}{*}{0.012} \\
\hline & $0(0)$ & 35 (28.9) & $86(71.1)$ & \\
\hline Primary school & $0(0)$ & 31 (41.9) & $43(58.1)$ & \\
\hline Intermediate school & $0(0)$ & $23(48.9)$ & $24(51.1)$ & \\
\hline High school or vocational & $0(0)$ & $7(63.6)$ & $4(36.4)$ & \\
\hline Institute and above & $0(0)$ & $6(66.67)$ & $3(33.33)$ & \\
\hline & \multirow[t]{5}{*}{0.434} \\
\hline Single & $0(0)$ & $8(50)$ & $8(50)$ & \\
\hline Married & $0(0)$ & $91(37.8)$ & $150(62.2)$ & \\
\hline Widow & $0(0)$ & $2(50)$ & $2(50)$ & \\
\hline Separated & $0(0)$ & $1(100)$ & $0(0)$ & \\
\hline
\end{tabular}




\section{DISCUSSION}

End stage renal failure (ESRF) is a chronic disease which causes a high level of hindrance in different aspects of the patient's life, leading to poor quality of life (QOL). End stage renal failure impacts QOL of patients with adverse effects observed in domains of symptoms/ problems, effects of kidney disease on daily life, burden of kidney disease, cognitive function, sexual function and sleep domains.

The mean age of ESRF patients undergoing HD in most developing countries is lower than that in developed countries [14]. The mean age of current study is $55.55( \pm 13.83)$ which agree with the result of previous study done on 286 patients with mean age of $54.71( \pm 14.12)$ [15]. The reasons behind this difference are the delay of detecting renal disease and failure to controlling and preventive renal failure, both of which result in faster deterioration of renal function and progression of ESRD.

More than half of the patients in this study were female, which is consistent with previous studies that showed more than half of correspondents were female[16]. The majority of patients ranged within the age groups of (48-62 years). This is in line with other studies that the majority of study sample was more than 40 years[14]. The results of present study revealed that the near of half of patients were illiterate. Which is in the line with the study carried out by Brzanji which aimed to assess quality of life for dialysis patients in Kirkuk city which showed that the more than half of patients were illiterate [17]. Regarding the marital status, most of the patients were married. Our finding was consistent with other study done in Nepal, aimed to assess QOL in patients undergoing hemodialysis and evaluated the effects of various sociodemographic factors affecting QOL in that the most of the participant were married
[18]. Regarding the residency, the majority of the study samples were from rural areas. Our result comes with other study done in the India [19].

The present study showed that the highest percentage of patients was ranked below average overall QOL scores; the remaining of the sample was ranked average QOL. The majority of the male and female sample was ranked below average, while in a comparison between male and female, the male patients have better QOL than female patients. The finding agrees with other study done in Brazil showed that women had lower QOL in physical role scores, symptoms/problems, physical functioning, emotional well-being, energy and fatigue mean score [15].

Acording to Ramatillah the reasons for poor QOL in women seem to be related to psychological and social factors, rather than the illness itself (20). The result showed that there is no significant relationship between gender of sample and overall QOL at $\mathrm{p}<0.05$.

More than half of the age group (48-62 years) ranked below average QOL. The finding is in line with other study done in Malaysia [20]. The result showed that there is no significant relationship between age groups of the sample and overall QOL at $\mathrm{p}<0.05$.

In association of overall QOL and level of education, the QOL level of majority of illiterate patients was ranked below average whereas minority of them were ranked average QOL. The results of present study showed that there is a significant relationship between level of education of the sample and overall QOL at $p<0.05$. The present study illustrate that the illiterate patient have poor QOL. The finding agrees with other studies done by VK Anu et al [12] and Joshi et al [16] were showed that illiterate patient have poor QOL. The possible reason behind this may be that 
Illiterate patients have poor knowledge regarding disease condition and its management so that they cannot implicate it on their lives for the better outcomes.

The results of the current study showed that the QOL levels of majority of married patients were ranked below average while more than one third of them were ranked average QOL. We found that the married patient have better $\mathrm{QOL}$ than unmarried patient, a finding consistent with other study [21]. In Erbil, due to extended family structure, even unmarried people usually get adequate emotional and financial support from their families, the emotional and financial support where is most often linked to marriage. The results of present study showed that there is no significant relationship between marital status of sample and overall QOL at $p<0.05$. The present study explored all domains that ranked below average QOL level except symptoms/problems and quality of social interaction domains which ranked average QOL level. The findings of this study agree with other studies because QOL scores were poor across all domains and the highest score was for quality of social interaction [22]. A similar trend of very low scores in burden of kidney disease domain and relatively good scores in symptom and problem domain have been noted in other study conducted by Kamau et al. [23].

\section{CONCLUSIONS}

The study stated that the majority of the hemodialysis patients there were below average level of QOL and the study found that there is a significant relationship between educational level and QOL.

\section{ACKNOWLEDGMENT}

We would like to thank all the patients who participated in this study and dialysis staff of Erbil Dialysis Centre and Dialysis Unit at Erbil Teaching Hospital, for their support and cooperation during the study period. We are especially thankful to Mr. Dara AlBanna for his role and contribution in data analysis.

\section{CONFLICTS OF INTEREST}

The authors report no conflict of interests.

\section{REFERENCES}

[1] aropadi AN, Mason G, Rettore E, Ronco C. Cost of peritoneal dialysis and haemodialysis across the world. Nephrology Dialysis Transplantation. 2013 Oct;28(10):2553-69.

[2] Shdaifat EA, Abdul Manaf MR. Quality of life among Jordanian patients on haemodialysis and their caregivers. BMC Public Health. 2012 Nov 27;12(2):A14.

[3] Romero M, Vivas-Consuelo D, Alvis-Guzman N. Is Health Related Quality of Life (HRQoL) a valid indicator for health systems evaluation? Springerplus. 2013 Dec 11;2:664.

[4] Kimmel PL, Patel SS. Quality of life in patients with chronic kidney disease: focus on end-stage renal disease treated with hemodialysis. Seminars in Nephrology. 2006 Jan;26(1):68-79.

[5] Sapkota A, Sedhain A, Rai MK. Quality of life of adult clients on renal replacement therapies in Nepal. Journal of Renal Care. 2013 Dec;39(4):228-35.

[6] Murtagh FEM, Addington-Hall J, Higginson IJ. The prevalence of symptoms in end-stage renal disease: a systematic review. Advances in Chronic Kidney Disease. 2007 Jan;14(1):82 $-99$.

[7] Wu AW, Fink NE, Marsh-Manzi JVR, Meyer $\mathrm{KB}$, Finkelstein FO, Chapman MM, et al. Changes in quality of life during hemodialysis and peritoneal dialysis treatment: generic and disease specific measures. Journal of the American Society of Nephrology. 2004 Mar;15(3):743-53.

[8] Johansen KL, Chertow GM, Kutner NG, Dalrymple LS, Grimes BA, Kaysen GA. Low level of self-reported physical activity in ambulatory patients new to dialysis. Kidney International. 2010 Dec;78(11):1164-70.

[9] Lee MB, Bargman JM. Survival by Dialysis Modality-Who Cares? Clinical journal of the American Society of Nephrology. 2016 Jun 6;11(6):1083-7. 
[10] Joshi VD. Quality of life in end stage renal disease patients. World Journal of Nephrology. 2014 Nov 6;3(4):308-16.

[11] KDQOL Complete [Internet]. [cited 2018 Jun 26]. Available from: https://www.kdqolcomplete.org/

[12] Anu VK, Pushpa P, Kumar SS. Quality of Life of Patients undergong Haemodialysis at B.P. Koirala Institute of Health Sciences. Journal of Manmohan Memorial Institute of Health Sciences. 2014 Feb 22;1(2):19-25.

[13] Oliveira APB, Schmidt DB, Amatneeks TM, Santos JCD, Cavallet LHR, Michel RB. Quality of life in hemodialysis patients and the relationship with mortality, hospitalizations and poor treatment adherence. Journal Brasileiro De Nefrologia. 2016 Dec;38(4):411-20.

[14] Yusop NBM, Mun CY, Shariff ZM, Huat CB. Factors Associated with Quality of Life among Hemodialysis Patients in Malaysia. PLOS ONE. 2013 Dec 16;8(12):e84152.

[15] Brzanji RYHRIAA-. Quality Of Life For Hemodialysis Patients In Kirkuk Governorate / Iraq. Kufa Journal for Nursing Sciences [Internet]. 2014 Feb 26 [cited 2018 Jun 25];3(3). Available from: http://www.uokufa.edu.iq/ journals/index.php/kjns/article/view/2245

[16] Joshi U, Subedi R, Poudel P, Ghimire PR, Panta $\mathrm{S}$, Sigdel MR. Assessment of quality of life in patients undergoing hemodialysis using WHOQOL-BREF questionnaire: a multicenter study. International Journal of Nephrology and Renovascular Disease. 2017;10:195-203.

[17] Manavalan M, Majumdar A, Harichandra Kumar KT, Priyamvada PS. Assessment of health-related quality of life and its determinants in patients with chronic kidney disease. Indian Journal of Nephrology. 2017;27 (1):37-43.

[18] Ramatillah DL, Syed Sulaiman SA, Khan AH, Meng OL. Quality of Life among Patients Undergoing Hemodialysis in Penang, Malaysia. Journal of Pharmacy And Bioallied Sciences. 2017;9(4):229-38.

[19] Ogutmen B, Yildirim A, Sever MS, Bozfakioglu $S$, Ataman R, Erek E, et al. Health-related quality of life after kidney transplantation in comparison intermittent hemodialysis, peritoneal dialysis, and normal controls. Transplantation Proceedings. 2006 Mar;38(2):419 $-21$.
[20] Abdelghany MA, Nienaa EEE and YA. Assessment of Health-Related Quality of Life in Patients Receiving Regular Hemodialysis. Journal of Nephrology \& Therapeutics [Internet]. 2016 Apr 9 [cited 2018 Jul 9];2016. Available from: https:// www.omicsonline.org/peer-reviewed/ assessment-of-healthrelated-quality-of-lifein-patients-receiving-regular-hemodialysis72051.html

[21] Kamau E, Kayima J, Otieno CF. The Determinants Of Health Related Quality Of Life Of Patients On Maintenance Haemodialysis At Kenyatta National Hospital, Kenya. East African Medical Journal. 2014 Oct;91(10):36874 